Jurnal Olahraga \& Kesehatan Indonesia

Volume 1 Nomor 2 (2021)

E-ISSN: 2747-061X

available online at https://jurnal.stokbinaguna.ac.id/index.php/jok

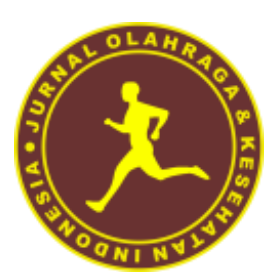

\title{
KORELASI KOORDINASI MATA TANGAN \\ DAN KEKUATAN OTOT LENGAN \\ TERHADAP SHOOTING BOLA BASKET
}

\author{
Reza Mahyuddin ${ }^{1}$ *, Akbar Sudirman ${ }^{2}$ \\ ${ }^{12}$ Universitas Negeri Makassar, Sulawesi Selatan, Indonesia, 90222 \\ *Coressponding Author: rezamahyuddin@unm.ac.id
}

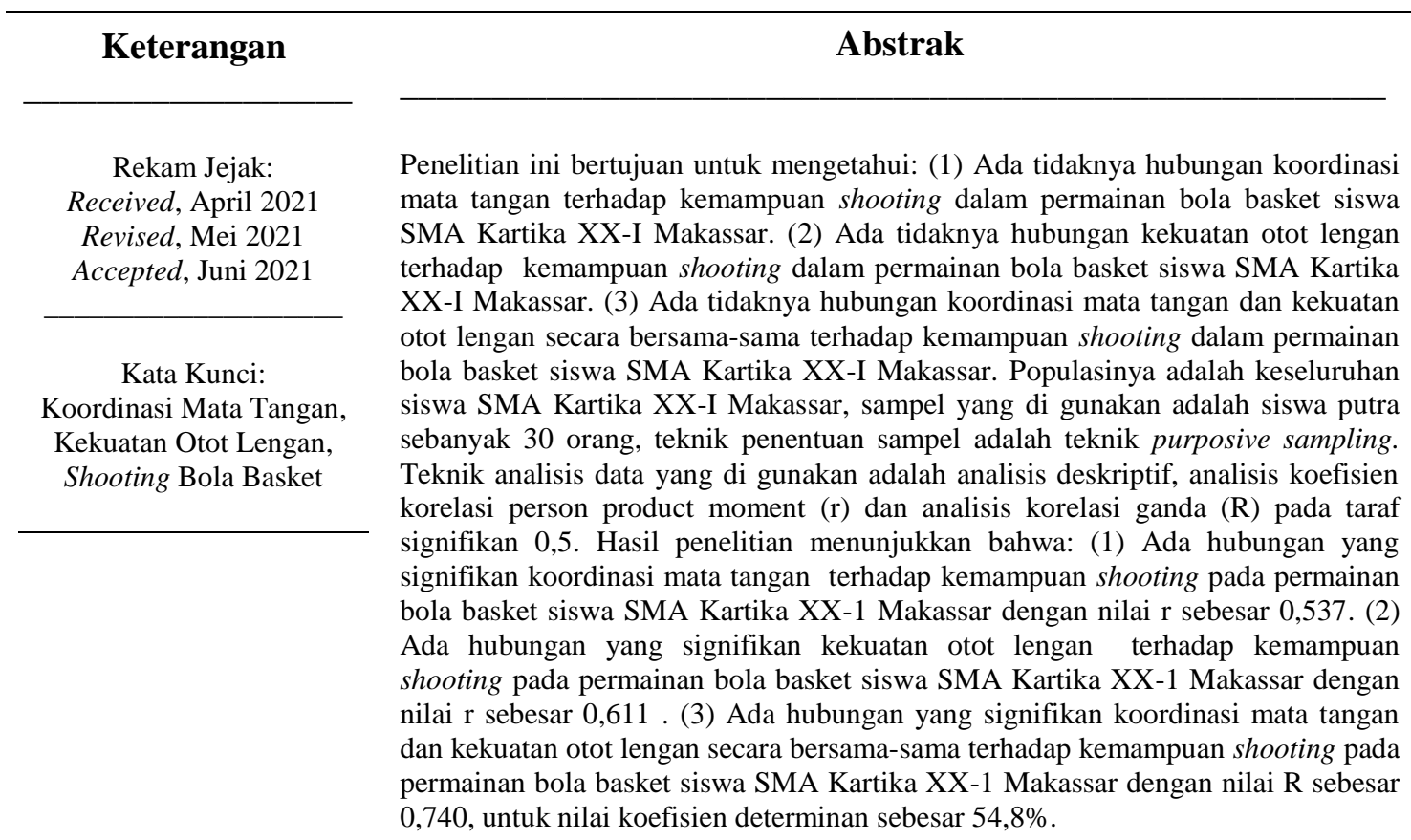

Copyright (C) 2020

Jurnal Olahraga \& Kesehatan Indonesia 


\section{PENDAHULUAN}

Ilmu pendidikan di sebut pedogogy yang merupakan terjemahan dari bahasa inggris yaitu "pedagogics". Pedagogics sendiri berasal dari bahasa yunani yaitu "pais" yang artinya anak dan "again" yang artinya membimbing. Dari arti tersebut dapat di pahami bahwa pendidikan mengandung pengertian "bimbingan yang di berikan pada anak". Orang yang memberikan bimbingan kepada anak di sebut pembimbing atau "pedagog". Dalam perkembanganya, istilah pendidikan (pedagogy) berarti bimbingan atau pertolongan yang di berikan kepada anak oleh orang dewasa secara sadar dan bertanggung jawab, baik mengenai aspek jasmaninya meupun aspek rohaninya menuju ke tingkat ke dewasaan anak. (paturusi, 2012:3). Menurut Ki Hajar Dewantara pendidikan yaitu tuntutan di dalam hidup tumbuhnya anak-anak, adapun maksudnya, pendidikan yaitu menuntut segala kekuatan kodrat yang ada pada anak-anak itu, agar mereka sebagai manusia dan sebagai anggota masyarakat dapatlah mencapai keselamatan dan kebahagiaan setinggi-tingginya.(Faturrahman dkk, 2012:2)

Pendidikan jasmani adalah proses pendidikan melalui penyediaan pengalaman belajar kepada siswa berupa aktivitas jasmani, bermain dan berolahraga yang di rencanakan secara sistematik guna meransang pertumbuhan dan perkembangan fisik, keterampilan monitorik, keteraampilan berfikir, emosional, social dan moral. Pembekalan pengalaman belajar itu di arahkan untuk membina sekaligus membentuk gaya hidup sehat dan aktif sepanjang hayat. (Rosdiani, 2015:1). Pembinaan olahraga di Indonesia selain untuk membentuk manusia Indonesia yang sehat fisik dan mental, juga menanam dan memupuk kejujuran, sportifitas. Dengan melakukan olahraga dapat menanam, memupuk dan mengembangkan sikap mental, kejujuran, keberanian, daya juang dan semangat bersaing, jiwa sportivitas yang didalamnya terkandung nilai-nilai pendorong generasi muda sebagai taman bangsa yang mampu tumbuh menjadi generasi yang baik dan berjiwa sehat dalam rangka mengisi kemerdekaan bangsa Indonesia. Menurut Cholik Mutohir (1992) Olahraga adalah proses sistematik yang berupa segala kegiatan atau usaha yang dapat mendorong mengembangkan, dan membina potensipotensi jasmaniah dan rohaniah seseorang sebagai perorangan atau anggota masyarakat dalam bentuk permainan, perlombaan/pertandingan, dan kegiatan jasmani yang intensif untuk memperoleh rekreasi, kemenangan, dan prestasi puncak dalam rangka pembentukan manusia Indonesia seutuhnya yang berkualitas berdasarkan pancasila (Rahayu, 2013:2).

Bola basket adalah olahraga bola berkelompok yang terdiri atas dua tim beraggotakan masing-masing lima orang yang saling bertanding mencetak poin dengan memasukkan bola ke dalam keranjang lawan. Olahraga ini biasanya di mainkan di ruangan olahraga tertutup dan hanya memerlukan lapangan yang relatif kecil. Olahraga basket relatif mudah di pelajari karna bentuk bolanya yang besar, sehingga tidak menyulitkan pemain ketika memantulkan atau melempar bola tersebut. (sutanto 2016; 42). Permainan bola basket adalah olahraga permainan bola berkelompok yang terdiri atas dua tim beranggotakan masing-masing 5 pemain yang saling bertanding mencetak poin dengan memasukkan permainan bola ke keranjang (ring) lawan. Permainan permainan bola basket adalah suatu permainan yang di lansungkan dalam suatu daerah berlantai keras dengan ukuran panjang tidak melebihi 94 kaki (kurang lebih 29 meter) dan lebar tidak melebihi 50 kaki (kurang lebih 16 meter) (Rustanto, 2017:76). Dalam permainan permainan bola basket, ada beberapa teknik dasar yang harus di kuasai, yaitu passing (mengoper), dribbling (mengiring) dan shooting (tembakan). Permainan permainan bola basket tidak terlepas dari teknik dasar permainan, salah satu macam teknik dasar dalam permainan permainan bola basket adalah shooting. Dalam permainan permainan bola basket, shooting adalah lemparan yang sangat penting perananya. Teknik shooting adalah sebuah gerakan yang di mana seorang pemain menembakkan permainan bola ke arah keranjang tim lawan. Berakhirnya sebuah teknik shooting ialah di mana seorang pemain melepaskan permainan bola dari tangannya menuju ring lawan dengan kaki yang menyentuh lantai setelah melakukan sedikit jumping (Khoeron, 2017:47). Dalam melakukan lemparan atau shooting sangat diperlukan antara koordinasi mata tangan dan kekuatan otot lengan dalam melakukannya. 
Berdasarkan pendapat di atas peneliti dapat menyimpulakan bahwa permainan bola basket adalah permainan bola besar yang terdiri dari dua tim yang masing-masing pemainya terdiri atas 5 orang yang saling bertanding mencetak poin sebanyak-banyaknya ke dalam ring lawan. dan permainan ini di lakukan di lantai yang keras yang lapangan relatif kecil, tidak terlepas dari teknik dasar permainan, salah satu macam teknik dasar dalam permainan permainan bola basket adalah shooting. Koordinasi mata tangan merupakan hubungan yang saling berkaitan atau pergabungan gerakan yang mana bermacam-macam gerakan yang berbeda di kelompokkan dalam suatu pola gerakan tunggal secara efektif (Handayani, 2018:259). Kekuatan otot lengan ialah yang mana kontraksi otot dalam usaha untuk mencapai tenaga yang maksimal dalam mengeluarkan tenaga atau menahan beban tersebut (Handayani 2018:261). Berdasarkan beberapa macam teknik dalam bermain permainan bola basket, peneliti tertarik melakukan penelitian tentang shooting pada permainan permainan bola basket. Seperti yang terjadi pada siswa SMA Kartika XX-1 Makassar, menurut pengamatan peneliti, siswa masih kurang mampu dalam melakukan shooting permainan bola basket. Hal ini terlihat pada proses pembelajaran pendidikan jasmani pada materi permainan bola basket, ada beberapa siswa yang memiliki shooting yang baik tetapi, ada juga siswa yang kurang baik dalam melakukan shooting. Agar menghasilkan shooting yang baik dibutuhkan latihan koordinasi mata tangan dan kekuatan otot lengan untuk meningkatkan kemampuan shooting dalam permainan permainan bola basket.

\section{METODE}

Jenis penelitian ini bersifat deskriptif. Penelitian ini dilakukan di SMA Kartika XX-I Makassar dan waktu penelitian ini pada semester ganjil tahun ajaran 2019/2020. Metode yang digunakan adalah metode kuantitatif. Populasi dalam penelitian ini adalah keseluruhan siswa SMA Kartika XX-I Makassar. Karena jumlah populasi dalam penelitian ini relatif banyak, maka peneliti membatasi dengan melakukan pemilihan menggunakan teknik purposive sampling dimana sampel di ambil berdasarkan kriteria tertentu, sehingga diperoleh jumlah sampel sebanyak 30 siswa putra. Instrumen yang digunakan dalam penelitian ini yaitu Tes koordinasi mata tangan (lempar tangkap bola tennis), Tes Kekuatan otot lengan (tes push up), dan Tes kemampuan shooting (set shot/free throw). Setelah seluruh data penelitian terkumpul yakni data koordinasi mata tangan, data kekekuatan otot lengan dan data kemampuan shooting pada permainan bola basket, maka untuk menguji hipotesis yang diajukan dalam penelitian ini, maka data tersebut disusun, diolah dan dianalisis statistik dengan bantuan komputer melalui program SPSS versi 20.

\section{HASIL \& PEMBAHASAN}

\section{Hasil}

Adapun data yang diperoleh dari hasil penelitian antara lain; data koordinasi mata tangan dari 30 jumlah sampel diperoleh nilai total 182 kali, mean sebesar 6,07 kali, median sebesar 6,00 kali, mode sebesar 6 kali dengan hasil standard deviasi $=1,143$ kali, nilai varians $=1,306$ kali, nilai range $=4$ kali, nilai minimum $=4$ kali dan nilai maximum 8 kali, data kekuatan otot lengan dari 30 jumlah sampel diperoleh nilai total $637 \mathrm{kali}$, mean sebesar 21,23 kali, median sebesar 21,00 kali, mode sebesar 21 kali dengan hasil standard deviasi $=2,079$ kali, nilai varians $=4,323 \mathrm{kali}$, nilai range $=8 \mathrm{kali}$, nilai minimum $=17 \mathrm{kali}$ dan nilai maximum $25 \mathrm{kali}$, dan data kemampuan shooting dari 30 jumlah sampel diperoleh nilai total 773 kali, mean sebesar 25,77 kali, median sebesar 26,00 kali, mode sebesar 26 kali dengan hasil standard deviasi $=2,161 \mathrm{kali}$, nilai varians $=4,668 \mathrm{kali}$, nilai range $=8 \mathrm{kali}$, nilai minimum $=22$ kali dan nilai maximum 30 kali.

Berdasarkan hasil pengujian normalitas data menggunakan uji kolmogorov smirnov dapat diketahui hasil untuk masing-masing variabel sebagai berikut; variabel koordinasi mata tangan menunjukan bahwa data tersebut berada pada sebaran normal, karena nilai yang diperoleh KS-Z 
$=0,968(\mathrm{P}=0,306>0,05)$, variabel kekuatan otot lengan menunjukan bahwa data tersebut berada pada sebaran normal, karena nilai yang diperoleh $K S-Z=0,610(P=0,851>0,05)$, dan variabel kemampuan shooting pada permainan bola basket menunjukan bahwa data tersebut berada pada sebaran normal, karena nilai yang diperoleh KS-Z $=0,601(\mathrm{P}=0,863>0,05)$. Setelah dilakukan uji persaratan normalitas pada hipotesis yang akan diuji, maka lebih lanjut dilakukan pengujian terhadap pengujian hipotesis, untuk membuktikan kebenarannya, hasil perhitungan statistik pada hipotesis penelitian diuraikan sebagai berikut; hasil analisis korelasi data koordinasi mata tangan terhadap kemampuan shooting dalam permainan bola basket diperoleh nilai korelasi $(\mathrm{r})=0,537$ dan nilai $\mathrm{F}=11,363$ dengan tingkat pobabilitas $(0,002)$ lebih kecil dari $\alpha=0,05$, maka $\mathrm{H}_{0}$ ditolak dan $\mathrm{H}_{1}$ diterima atau koefisien korelasi signifikan, atau koordinasi mata tangan benar-benar memiliki hubungan secara signifikan terhadap kemampuan shooting dalam permainan bola basket, hasil analisis korelasi data kekuatan otot lengan terhadap kemampuan shooting dalam permainan bola basket diperoleh nilai korelasi $(r)=0,611$ dan nilai $\mathrm{F}=16,702$ dengan tingkat probabilitas $(0,000)$ lebih kecil dari $\alpha=0,05$, maka $\mathrm{H}_{0}$ ditolak dan $\mathrm{H}_{1}$ diterima atau koefisien korelasi signifikan, atau kekuatan otot lengan benar-benar memiliki hubungan secara signifikan terhadap kemampuan shooting dalam permainan bola basket, dan hasil analisis regresi ganda data koordinasi mata tangan dan kekuatan otot lengan terhadap kemampuan shooting dalam permainan bola basket diperoleh nilai Regresi $(\mathrm{R})=0,740$ dan nilai $\mathrm{F}=16,379$ dengan tingkat pobabilitas $(0,000)$ lebih kecil dari $\alpha=0,05$, maka $\mathrm{H}_{0}$ ditolak dan $\mathrm{H}_{1}$ diterima atau koefisien regresi ganda signifikan, atau koordinasi mata tangan dan kekuatan otot lengan benar-benar memiliki hubungan secara signifikan terhadap kemampuan shooting dalam permainan bola basket.

\section{Pembahasan}

Hipotesis pertama $\mathrm{H}_{0}$ ditolak dan $\mathrm{H}_{1}$ diterima yaitu ada hubungan koordinasi mata tangan terhadap kemampuan shooting dalam permainan bola basket siswa SMA Kartika XX-1 Makassar, hal tersebut diperkuat dengan hasil analisis korelasi bahwa nilai $r=0,537$. Dapat dikatakan bahwa makin bagus koordinasi mata tangan yang dimiliki seseorang maka akan bagus pula saat kemampuan shooting dalam permainan bola basket. Menurut Prastyoanam (2017:10) Koordinasi mata tangan adalah kombinasi seseorang dalam mengamati objek dengan keterampilan tangan dalam berintraksi dengan objek tersebut, yang akan di ukur dengan lempar tangkap bola ke tembok yaitu seberapa banyak lemparan yang berapa bisa tepat ke sasaran dan berhasil di tangkap kembali dalam waktu 30 detik.

Menurut Handayani koordinasi mata tangan (2018:260) merupakan hubungan yang saling berkaitan atau pergabungan gerakan yang mana bermacam-macam gerakan yang berbeda di kelompokkan dalam suatu pola gerakan tunggal secara efektif. Koordinasi mata tangan sangat diperlukan dalam permainan bola basket dalam melakukan shooting dimana pada saat bola ditembakkan ke ring lawan teknik yang digunakan pemain harus benar-benar mempunyai kemampuan koordinasi yang baik. Tingkat koordinasi atau baik tidaknya koordinasi gerak seseorang tercermin dalam kemampuannya untuk melakukan suatu gerakan secara mulus, tepat (precise), dan efisien. Seorang atlet dengan koordinasi yang baik bukan hanya mampu melakukan suatu keterampilan secara sempurna, akan tetapi juga mudah dan cepat dapat melakukan keterampilan yang masih baru baginya. Dia juga dapat mengubah dan pindah secara tepat dari pola gerak yang satu ke pola gerak yang lain sehingga gerakannya menjadi efisien.

Hipotesis kedua H0 ditolak dan H1 diterima yaitu: ada hubungan kekuatan otot lengan terhadap kemampuan shooting dalam permainan bola basket siswa SMA Kartika XX-1 Makassar, hal tersebut diperkuat dengan hasil analisis korelasi bahwa nilai $r=0,611$. Dapat dikatakan bahwa makin bagus kekuatan otot lengan yang dimiliki seseorang maka akan bagus pula saat kemampuan shooting dalam permainan bola basket.

Menurut Prastyoanam (2017:10) Kekuatan otot lengan adalah kemampuan seseorang untuk menggerakan daya semaksimal mungkin untuk mengatasi sebuah tahanan. Menurut 
Handayani (2018:261) Kekuatan otot lengan ialah yang mana kontraksi otot dalam usaha untuk mencapai tenaga yang maksimal dalam mengeluarkan tenaga atau menahan beban tersebut.

Kekuatan otot lengan juga sangat mempengaruhi dalam permainan bola basket, permainan bola basket sangat memerlukan kekuatan otot lengan dalam melakukan teknik bermain bola basket seperti shooting dimana setiap tembakan atau shooting harus menggunakan kekuatan otot lengan sehingga pemain mendapatkan shooting yang maksimal. Kekuatan merupakan kontraksi yang maksimal untuk menerima beban yang dihasilkan oleh otot atau sekelompok otot. Kekuatan merupakan salah satu unsur kondisi fisik yang sangat dominan dan sangat dibutuhkan dihampir semua cabang olahraga. Pelaksanaan berbagai macam keterampilan atau aktivitas gerak khususnya dalam bermain bola basket, seorang pemain harus terlebih dahulu memiliki dasar kekuatan yang baik. Dasar kekuatan yang baik akan memudahkan pelaksanaan gerak baik di dalam melempar maupun di dalam menyongsong bola, melangkah dan atau meloncat, dan gerakan lain yang diperlukan dalam permainan bola basket. Hal ini semakin tampak jelas dengan manfaat yang diperoleh dari kekuatan yang baik yaitu untuk mempermudah mempelajari teknik serta mencegah kemungkinan terjadinya cidera.

Hipotesis ketiga $\mathrm{H}_{0}$ ditolak dan $\mathrm{H}_{1}$ diterima yaitu: ada hubungan koordinasi mata tangan dan kekuatan otot lengan terhadap kemampuan shooting dalam permainan bola basket siswa SMA Kartika XX-1 Makassar, hal tersebut diperkuat dengan hasil analisis regresi ganda bahwa nilai $(\mathrm{R})=0,740$. Dapat dikatakan bahwa makin bagus koordinasi mata tangan dan kekuatan otot lengan yang dimiliki seseorang maka akan bagus pula saat kemampuan shooting dalam permainan bola basket. Gerakan shooting ini bukan hanyalah sekedar asal melemparkan bola saja, tetapi juga meliputi gerakan mengarahkan dan mengusahakan agar bola jatuh tepat di sasaran. Semua gerakan mengarahkan ini, terutama dengan satu tangan kearah target yang tingginya di atas kepala, merupakan dasar dari keterampilan ini, berlatih mengarahkan bola sedemikian rupa, sehingga bola jatuh tepat masuk ke dalam keranjang. Yang biasa dilakukan dari jarak dekat maupun jarak jauh (Ambler, 2013:13).

Teknik shooting adalah sebuah gerakan yang dimana seorang pemain menembakkan bola kearah keranjang tim lawan. Berakhirnya sebuah teknik shooting ialah dimana seorang pemain telah melepaskan bola dari tangannya menuju ring lawan dengan kaki yang menyentuh lantai setelah melakukan sedikit jumping (Khoeron, 2017:47). Dalam melakukan shooting sangat dibutuhkan kondisi fisik yang optimal. Kondisi fisik ini meliputi koordinasi mata tangan, kekuatan otot lengan dan organ-organ gerak lainnya sebagai pendukung untuk melakukan serangkaian gerakan pada saat melakukan shooting. Untuk lebih spesifiknya bagian-bagian tubuh yang terlibat secara langsung pada saat melakukan shooting adalah dan koordinasi mata tangan dan kekuatan otot lengan. Berdasarkan hasil penelitian menunjukkan bahwa koordinasi mata tangan dan kekuatan otot lengan memberikan hubungan yang signifikan terhadap kemampuan shooting pada siswa SMA Kartika XX-1 Makassar yaitu sebesar 54,8\% dan sisanya sebesar $45,2 \%$ ditentukan oleh variabel lain.

\section{SIMPULAN}

Berdasarkan hasil analisis data dan pembahasan maka dapat diambil sebagai simpulan penelitian sebagai berikut; ada hubungan yang signifikan koordinasi mata tangan terhadap kemampuan shooting pada permainan bola basket siswa SMA Kartika XX-1 Makassar, ada hubungan yang signifikan kekuatan otot lengan terhadap kemampuan shooting pada permainan bola basket siswa SMA Kartika XX-1 Makassar, dan ada hubungan yang signifikan koordinasi mata tangan dan kekuatan otot lengan secara bersama-sama terhadap kemampuan shooting pada permainan bola basket siswa SMA Kartika XX-1 Makassar.

\section{DAFTAR PUSTAKA}

Aji, Sukma. (2016). Buku Olahraga Paling Lengkap. Jakarta: Ilmu. Amber, Vic. (2013). Petujuk Untuk Pelatihan Bola Basket. Bandung: Pionir Jaya 
Faturrahman, dkk. (2012). Pengantar Pendidikan. Jakarta: PT Prestasi Pustakaraya

Fenanlampir, Albertus. (2015). Tes Dan Pengukuran Dalam Olahraga. Yogyakarta: Andi.

Gustiawan, Danny Emmas. (2016). Hubungan Antara Koordinasi Mata Tangan Dan Kekuatan Otot Lengan Dengan Ketepatan Shooting Pada Permainan Bolabasket Siswa Putra Kelas XI SMK PGRI 4 Kediri. Kediri: Universitas Nusantara PGRI.

Handayani, Widya. (2018). Hubungan Antara Koordinasi Mata Tangan Dan Kekuatan Otot Lengan Dengan Ketepatan Hasil Servis Forehand Dalam Permainan Bulu Tangkis Pada Peserta Ekstrakurikuler di SMA Negeri 2 Kayuagung. Wahana Didaktika.

Harinaldi. (2005). Prinsip-Prinsip Statistik Untuk Teknik Dan SAINS. Jakarta: Erlangga.

Khoeron, Nidhom. (2017). Buku Pintar Basket. Jakarta: Anugrah.

Oliver, Jon. (2009). Dasar-Dasar Bola Basket. Bandung: Pakar Raya

Paturusi, Achmad. (2012). Manajemen Pendidikan Jasmani dan Olahraga. Jakarta: PT Rineka Cipta.

Prastyoanam, Siswo Eko. (2017). Hubungan Antara Kekuatan Otot Lengan Dan Koordinasi Mata Tangan Dengan Ketepatan Servis Atas Siswa Yang Mengikuti Ekstrakurikuler Bolavoli Di Smp Negeri 2 Balen Bojonegoro. Universitas Nusantara PGRI Kediri.

Rahayu, Trisna Ega. (2013). Strategi Pembelajaran Pendididkan Jasmani. Bandung: Alfabeta Rosdiani, Dini. (2015). Kurikulim Pendididkan Jasmani. Bandung: Alfabeta.

Rustanto, Heri. (2017). Meningkatkan Pembelajaran Shooting Bola Basket Dengan Menggunakan Media Gambar. IKIP PGRI Pontianak.

Sarwono. (2010). Pintar Menulis Karangan Ilmiah. Yogyakarta: Andi.

Stokes. (2006). How To Do Media And Cultural Studies. Yogyakarta: Bentang.

Sugiyono. (2018). Metode Penelitian kuantitatif. Bandung: CV Alfabeta.

Susilawati, Dewi. (2018). Tes Dan Pengukuran. Sumedang: UPI Sumedang Press.

Sutanto. (2016). Buku Pintar Olahraga. Yogyakarta: Pustaka Baru Press. 